\title{
Oral Health of Young Adolescents in Addis Ababa-A Community-Based Study
}

\author{
Hanna Yemane Berhane1, Alemayehu Worku² \\ ${ }^{1}$ Public Health and Social Sciences Department, Addis Continental Institute of Public Health, Addis Ababa, \\ Ethiopia \\ ${ }^{2}$ Epidemiology and Biostatistics Department, School of Public Health, Addis Ababa University, Addis Ababa, \\ Ethiopia \\ Email: hannayemane@addiscontinental.edu.et, ym1hanna@gmail.com, alemayehuwy@yahoo.com
}

Received 27 June 2014; revised 25 July 2014; accepted 5 August 2014

Copyright (C) 2014 by authors and Scientific Research Publishing Inc.

This work is licensed under the Creative Commons Attribution International License (CC BY). http://creativecommons.org/licenses/by/4.0/

(c) (i) Open Access

\section{Abstract}

Introduction: Deteriorating oral health is an emerging public health concern in developing countries, yet little attention has been given to oral health in most sub-Saharan countries. The extents of caries, periodontal diseases and the associated risk factors have not been widely studied at the community level. Purpose: To assess the type and magnitude of oral health diseases as well as associated risk factors among young adolescents in Addis Ababa, Ethiopia. Methods: A community-based cross-sectional study was conducted on a sample of 658 children aged $10-14$ years in Addis Ababa. Households for the study were selected through a multistage cluster sampling procedure. Data collection was carried out in December 2011 through interview and oral examination which was carried out by dental health professionals. Prevalence and $95 \%$ confidence interval was calculated. Factors associated with oral health conditions were identified using logistic regression. Results: The prevalence of dental caries was $47.4 \%$ (95\% CI: $43.6 \%-51.2 \%)$. Age, sweets intake, tooth cleaning, poor oral hygiene and being from a poor household were significantly associated with having dental caries. The prevalence of periodontal disease was $35.4 \%$ (95\% CI: $31.7 \%$ - 39.0\%) and it was associated with: having a mother with low education level, and poor oral hygiene. The prevalence of bad mouth odor was $4.4 \%$ (95\% CI: $2.8 \%-5.9 \%)$, and oral trauma $2.1 \%$ (95\% CI: 1\% - 3.2\%). Conclusion: The prevalence of both periodontal disease and dental caries is alarmingly high. The findings indicate the need for large scale public education program to motivate regular dental check up, and proper oral hygiene practices. The study also indicates the need to strengthen oral health services using affordable and accessible outlets.

\section{Keywords}

Oral Health, Dental Caries, Young Adolescents, Ethiopia 


\section{Introduction}

Oral health problems are among the most common health problems in the world. The most common oral health problem is dental caries, which especially affects developing countries [1]. It affects about $60 \%-90 \%$ of school children. Gingivitis is another cause of oral problems in school children. Oral trauma also occurs in 10\% - 15\% children. These traumas usually occur due to road traffic accidents or violence and unsafe playgrounds [2].

Untreated oral health problems can cause serious disruption in everyday life of the affected individuals and the society. Poor oral health affects people both physically and psychologically. In addition, oral diseases have economic consequences as they have high treatment cost, loss to work day for adults accompanying the child and also lead to loss of school days, consequently diminishing ability to learn [3].

Most oral diseases can be easily prevented with the implementation of simple preventive measures, including use of sealants to safe coat pits and fissures, fluoride supplementation, water and milk fluoridation, and reducing sweet consumption [4]. Though, oral hygiene is believed to be easy to practice and effective in preventing oral health problems, there is evidence that it is not satisfactorily practiced among school-age children [5].

The oral health services in sub-Saharan Africa are characterized by few oral health care personnel and urban concentration, typically leaving the rural and peri-urban communities with emergency care only. The presence of many life-threatening health problems and vast developmental needs contribute to the low priority given to oral health problems in the area [6].

Accordingly, community-based oral health assessment to determine the prevalence of various dental diseases as well as factors associated with them has not been conducted in Addis Ababa. Thus it was imperative to undertake a well designed cross-sectional study to determine the types and magnitude of oral health problem among young adolescents. Identifying the factors linked also helps to tackle the problem from an early age [7]. The objectives of this study were, therefore to determine the magnitude and factors associated with dental caries and periodontal disease.

\section{Methods}

This cross-sectional study was conducted in December 2011 in Addis Ababa, the capital of Ethiopia, whose population is about 3 million. The residents of the city comprise a wide range of ethnic, religious, economic and cultural backgrounds [8]. The city is divided into ten sub-cities and each one has around ten districts (Woreda), for a total of 116 .

The study population was selected using cluster multistage sampling procedures. The primary sampling unit included all 116 districts in Addis Ababa, which were arranged alphabetically to serve as a sampling frame. From this, 10 districts were selected using simple random sampling, from which we drew our study population. The sample was proportionally allocated for each selected district. Study participants were selected from consecutive households until the required number (quota) was obtained from each district during data collection.

Sample size calculation was made for the various objectives of the study to ensure adequate sample size for reasonably stable analysis. A total sample size of 658 was determined by using the formula for estimating single population proportion for cross-sectional survey. For determining the factors associated with various oral health problems; EPI Info module for calculating sample size for cohort or cross-sectional was used. The sample size requirement calculated considering various scenarios were less than the sample size calculated for the prevalence estimation, thus the larger sample size was taken for this study.

All children aged 10 - 14 years permanently residing in the selected household for at least 6 months and for whom consent was obtained were included in the study. Children with mental disabilities and those with severe illness were excluded, because of difficulties in carrying out oral examination. All children who participated in the study were accompanied by parents or legal guardians during data collection.

Data were collected using an interviewer-administered structured questionnaire and basic oral examination. The questionnaire was prepared based on the literature [9]-[11]. The questionnaire was first prepared in English and then translated to Amharic (the national language). The translated questionnaire was reviewed by three individuals to check its consistency and conceptual equivalence. Prior to the actual study, which was carried out in December 2011; a pretest was conducted in a district that was not included in the study.

The oral examination was performed by qualified dental professionals with degrees in Dental Health Science. The examination was carried out using a glove and wooden spatula in natural light. Basic hygienic procedures 
were observed during oral examination, and sterile examination materials were used for each study participant. The teeth were examined for dental caries by the presence of decay (D), missing (M) and filled teeth (F). Dental caries experience was measured by calculating the mean number of DMFT (decayed, missing, or filled tooth), in addition to calculating the prevalence.

For periodontal status, the child was considered to have periodontal disease when gingival bleeding was reported. After the oral examination, the children were asked if they often (in more than one incidence) encounter bleeding while brushing their teeth. If their response is "yes" then the child was said to have gingivitis, which is a mild form of periodontitis. Though periodontal probes were the best way to detect periodontal disease, the use of probes was not a feasible option for the study setting.

The presence and absence of dental trauma and perceived mouth odor were also recorded. Oral trauma was defined as an injury to the mouth, including teeth, lips, gums, tongue and jawbones. All visible traumas, which were usually seen as broken tooth or cracked lip, and their causes were reported after asking for the history. Bad mouth odor, was defined as unpleasant odors exhaled while breathing; this was reported by the child. The child was asked: "if they think they have an unpleasant odor while exhaling" if they respond "yes" they were considered as having bad mouth odor. Both bad mouth odor and cause of trauma were self reported.

Oral hygiene status of the child was evaluated as good/poor. They were labeled as having good oral hygiene; if no food particles and no accumulation of dental plaque and/or calculus is visible on the tooth surfaces at the time of oral examination. Poor oral hygiene, if presence of food particles in the mouth and there is a visible accumulation of dental plaque and/or calculus on the tooth surfaces at the time of oral examination.

For the knowledge score; both the parents and children were asked ten "yes/no" questions about causes and prevention of caries and gingivitis to assess their knowledge regarding oral health (scores 0 - 10). These questions were then graded/scored as: those who got a score greater than the mean (greater than five) as having "good knowledge" and those who got less or equal to five as having "poor knowledge".

After completion of the data collection, each questionnaire was edited, coded, and cleaned before it was entered onto a computer and analyzed using EPI-INFO version 3.5.1 and SPSS version 15. Bivariate logistic regression was conducted for each factor and those factors with P-value $<0.2$ were included in the multiple logistic regression model, which was used to control for confounding effects while determining the association between various oral health problems and the selected risk factors.

Ethical approval for this study was obtained from the University of Gondar. The necessary permission and letter of support were requested and obtained from all administrative bodies in Addis Ababa. Verbal informed consent was obtained from parents and children after providing complete information about the purpose and procedures of the study. At the end of the data collection session, all study participants were advised on how they can maintain their oral hygiene. Those who were identified as having oral health problem were advised to seek treatment in a nearby dental health facility.

\section{Results}

A total of 658 children aged 10 - 14 years participated in the study; among whom 348 (53.4\%) were female and nearly all 643 (97.7\%) attended school. According to the reported household expense, only 130 (21\%) had monthly expenditure $>2000$ birr per month meaning; $79 \%$ of the households live on a monthly expense of about 100 USD. Two hundred forty eight (37.7\%) of the households reported having five to six family members living in the household (Table 1).

Almost all 610 (92.7\%) of the children clean their teeth; 352 (57.7\%) used a local twig brush called "Mefakiya” and 221 (36.2\%) used a tooth brush. More than half 344 (57.8\%) cleaned their teeth once or a few times a week and 227 (38.3\%) reported using fluoride tooth paste. The main reason mentioned for not cleaning their teeth is "I always forget" (48.9\%).

Five hundred forty seven (83.1\%) have never visited a dentist. Among those who have visited a dentist, most went for emergency treatment 46 (41.4\%) and extraction 24 (21.6\%) (Table 2).

The prevalence of dental caries among young adolescents was $47.4 \%$ (95\% CI: 43.6\% - 51.2\%). The most affected teeth with dental caries were the molars. The total of decayed molars was 216 (49.4\%), with the mandibular first right and left molars the most affected. The total of incisors decayed was 41 (9.4\%), with canines 27 (6.2\%) and premolars 153 (35\%). The mean DMFT was 1.85. 
Table 1. Socio-demographic characteristics of young adolescents in Addis Ababa, Ethiopia, December 2011.

\begin{tabular}{ccc}
\hline & Characteristics & Number (\%) \\
\hline Age $(\mathrm{n}=657)$ & 10 & $151(23.0)$ \\
& 11 & $107(16.3)$ \\
& 12 & $158(24.0)$ \\
Sex $(\mathrm{n}=652)$ & 13 & $122(18.6)$ \\
& 14 & $119(18.1)$ \\
& Male & $304(46.6)$ \\
Child go to school ( $\mathrm{n}=658)$ & Female & $348(53.4)$ \\
& Yes & $643(97.7)$ \\
Type of school $(\mathrm{n}=642)$ & No & $15(2.3)$ \\
& Government & $325(50.6)$ \\
Average monthly expenditure $(\mathrm{n}=620)$ & Public & $86(13.4)$ \\
& Private & $231(36.0)$ \\
& $<500$ & $93(15.0)$ \\
Family member living in the & $500-1000$ & $180(29.0)$ \\
household $(\mathrm{n}=658)$ & $1000-2000$ & $217(35.0)$ \\
& $>2000$ & $130(21.0)$ \\
& $2-4$ & $200(30.4)$ \\
\end{tabular}

Periodontal disease was seen in 35.4\% (95\% CI: 31.7\% - 39.0\%) of the children. Prevalence of self reported bad mouth odor was 4.4\% (95\% CI: 2.8\% - 5.9\%) and oral trauma 2.1\% (95\% CI: 1\% - 3.2\%), with “falling” reported as the primary cause. Poor oral hygiene observed in $60.3 \%$ of the children (Figure 1).

We found a statistically significant association between dental caries and children among the age of 10 - 11 years; 10 year olds $(\mathrm{AOR}=1.75 ; 95 \% \mathrm{CI}$ : $(1.03$ - 2.98) and 11 year olds $(\mathrm{AOR}=1.86$; 95\% CI: $(1.05$ - 3.31$)$ ). Likelihood of having of dental caries was higher among those who consumed sweets than those who don't (AOR = 1.94; 95\% CI: (1.22, 3.09)). Having poor oral hygiene also increased the likelihood of having dental caries $(\mathrm{AOR}=1.59 ; 95 \% \mathrm{CI}:(1.12,2.26))$. On the other hand, tooth cleaning (AOR = 0.47; 95\% CI: (0.23 - 0.96)) and having monthly expenditures of less than 500 have shown to be protective factors against dental caries (AOR = 0.51; 95\% CI: $(0.28-0.90)$ ) (Table 3).

In the multivariate analysis; mother's education was significantly associated with periodontal disease. Young adolescents who have mothers with low education level are more likely to have periodontal disease; than those with mothers who have attended at least high school. For mothers who attended grade 1 - 8 (AOR = 2.71; 95\% CI: $(1.06,6.94)$ ) and for those who have never attended school (AOR = 3.17; 95\% CI: (1.14, 8.81)). Another important factor which was found to be associated with periodontal disease was poor oral hygiene (AOR = 3.13; 95\% CI: (1.98 - 4.93)) (Table 4).

\section{Discussion}

This study found that dental caries and periodontal disease were highly prevalent in the sample of young adolescents in Addis Ababa. The major factors were age, sweet intakes, poor oral hygiene, mother's educational level and economic status of the household.

The prevalence of dental caries observed in this study is nearly 3 times higher than a study done previously in Addis Ababa among school children 12 year and above, which was 21.1\% [12]. That study was conducted twelve years back and was a school based study. So, this dissimilarity in method, reference period as well as study setting may be a factor for the variation in the prevalence. The increasing availability and consumption of sugary beverages in urban areas could be attributed to increasing prevalence of oral health problems [13] [14].

Additionally, recent studies indicated increasing prevalence of dental caries mainly due to increased consumption of more refined and sugary foods. Sugar play a key role in the increasing rate of dental decay in Ethiopia; "prior to the commencement of the national production of sugar in 1958, the prevalence of caries was very 
Table 2. Oral hygiene and dental care-seeking practices of young adolescents in Addis Ababa, December 2011.

\begin{tabular}{|c|c|c|}
\hline & Characteristics & Number (\%) \\
\hline \multirow{3}{*}{ Tooth cleaning $(\mathrm{n}=658)$} & Yes & $610(92.7)$ \\
\hline & No & $48(7.3)$ \\
\hline & It bothers me & $7(15.6)$ \\
\hline \multirow{2}{*}{ Reason for not cleaning $(n=45)$} & Don't know the benefit of cleaning teeth & $7(15.6)$ \\
\hline & I always forget & $22(48.9)$ \\
\hline \multirow{5}{*}{ Clean your teeth with $(n=610)$} & Other & $9(19.9)$ \\
\hline & Tooth brush & $221(36.20)$ \\
\hline & Mefakia & $352(57.7)$ \\
\hline & Other & $37(6.0)$ \\
\hline & Once a week & $115(19.3)$ \\
\hline \multirow{2}{*}{ Frequency of teeth cleaning $(\mathrm{n}=595)$} & Few times a week & 229 (38.5) \\
\hline & Once a day & $194(32.6)$ \\
\hline \multirow{3}{*}{$\begin{array}{l}\text { Use of fluoride containing tooth paste } \\
\qquad(\mathrm{n}=592)\end{array}$} & Other & $57(9.6)$ \\
\hline & Yes & $227(38.3)$ \\
\hline & No & $365(61.7)$ \\
\hline \multirow{4}{*}{ Frequency of dental visit $(n=658)$} & Regularly every 6 - 12 months & $21(3.2)$ \\
\hline & 0ccassionally & $14(2.1)$ \\
\hline & Only with dental pain & $76(11.6)$ \\
\hline & Never visited a dentist & $547(83.1)$ \\
\hline \multirow{4}{*}{$\begin{array}{l}\text { Treatment sought during the last dental } \\
\text { visit }(\mathrm{n}=111)\end{array}$} & Check up, examination, cleaning & $23(20.7)$ \\
\hline & Routine treatment & $18(16.2)$ \\
\hline & Emergency treatment & $46(41.4)$ \\
\hline & Extraction & $24(21.6)$ \\
\hline \multirow{2}{*}{$\begin{array}{l}\text { Felt scared during the first dental } \\
\text { visit }(\mathrm{n}=108)\end{array}$} & Yes & 75 (69.4) \\
\hline & No & 33 (30.6) \\
\hline \multirow{2}{*}{$\begin{array}{l}\text { Going to a dentist is synonymous } \\
\text { with pain }(\mathrm{n}=615)\end{array}$} & Yes & $284(46.2)$ \\
\hline & No & 331 (53.8) \\
\hline
\end{tabular}

low. Today; there is an increasing demand to sugary products, the use of sugar as a sweetener in tea, coffee and milk is very common" [15]. The mechanism for teeth destruction due to sugar intake has been well established; sugary diet tends to attach to the tooth surface making it easier for the bacteria's to attach. The bacteria then convert glucose, fructose, and most commonly sucrose (table sugar) into acids. If left in contact with the tooth, these acids cause demineralization of the hard tissues of the teeth.

Among the socio demographic factors age of the child was associated with dental caries. A possible explanation for this may be: by age 12 a child will shed of most of the milk tooth and replace it with permanent teeth; which is relatively new in the oral cavity and caries free. It was seen in this study that children aged 10 - 11 are more affected by caries as compared to those children with age greater than 12. Additionally as the age of the child increases; the child will be more concerned about his/her personal hygiene [5].

Poor economic status was protective from dental caries; this may be due to less exposure to sweets (candy, cakes). This finding is contrary to a study in Lima, Peru which suggests that children living in poor households are more likely to have dental caries. The study tries to explain this link indicating the impact of material deprivation on dental caries [16]. Also dental caries was found to be significantly associated to poor oral hygiene. This is in agreement with other studies [12] [13].

The high prevalence of calculus; despite the fact that more than $90 \%$ of the study participants claim to clean their teeth indicates that the tooth cleaning is not adequate or the techniques used are not proper. Among those 


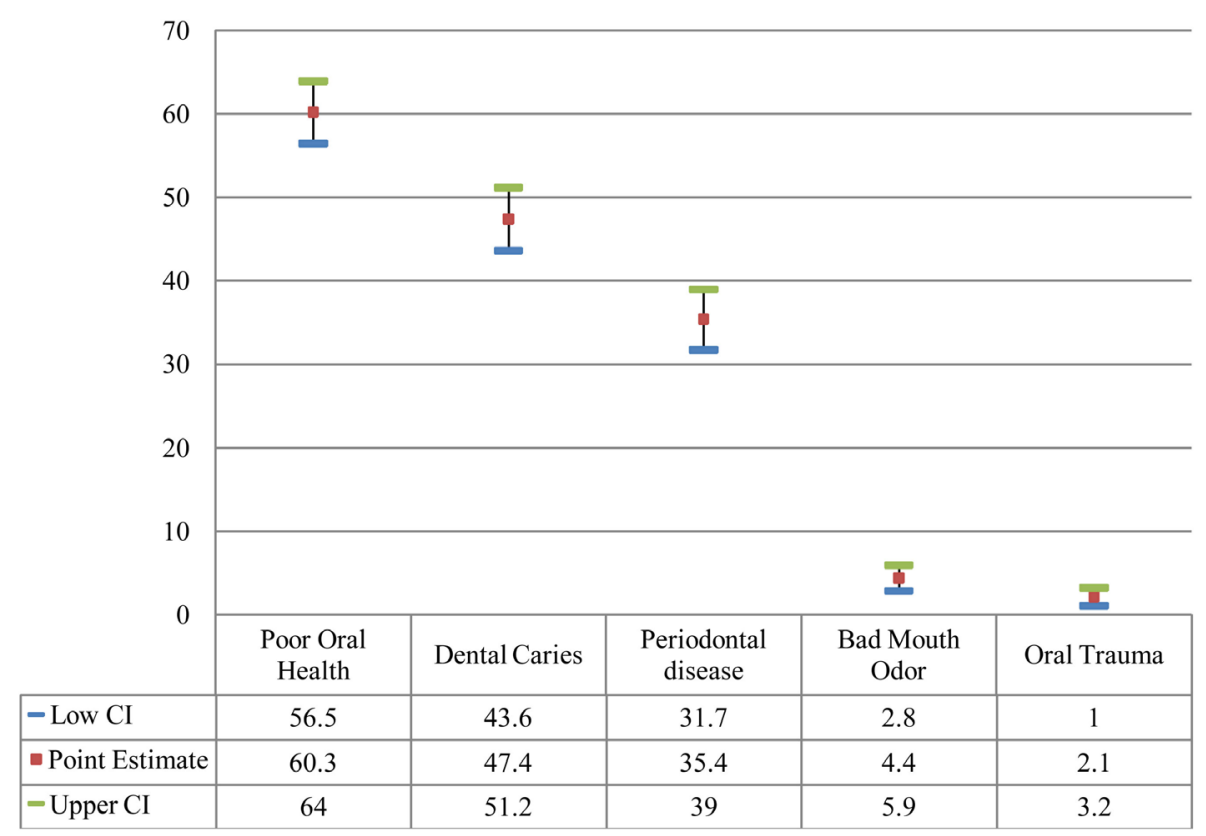

Figure 1. Prevalence of oral health problems among young adolescents in Addis Ababa, December 2011.

Table 3. Factors associated with dental caries among young adolescents in Addis Ababa, December 2011.

\begin{tabular}{|c|c|c|c|c|c|}
\hline \multirow{2}{*}{\multicolumn{2}{|c|}{ Factor }} & \multicolumn{2}{|c|}{ Dental caries } & \multirow{2}{*}{ COR $(95 \%$ CI) } & \multirow{2}{*}{ AOR (95\% CI) } \\
\hline & & Yes & No & & \\
\hline \multirow{5}{*}{ Age } & 10 & 83 & 68 & $2.23(1.36-3.66)$ & $1.75(1.03-2.98)$ \\
\hline & 11 & 59 & 48 & $2.25(1.31-3.84)$ & $1.86(1.05-3.31)$ \\
\hline & 12 & 74 & 84 & $1.61(0.99-2.63)$ & $1.43(0.84-2.42)$ \\
\hline & 13 & 54 & 68 & $1.45(0.86-2.44)$ & $1.25(0.72-2.18)$ \\
\hline & 14 & 42 & 77 & 1.00 & 1.00 \\
\hline \multirow{4}{*}{$\begin{array}{l}\text { Average monthly } \\
\text { expenditure }\end{array}$} & $<500$ & 37 & 56 & $0.56(0.33-0.97)$ & $0.51(0.28-0.90)$ \\
\hline & $500-1000$ & 78 & 102 & $0.65(0.41-1.03)$ & $0.62(0.38-1.00)$ \\
\hline & $1000-2000$ & 113 & 104 & $0.93(0.60-1.44)$ & $0.84(0.53-1.34)$ \\
\hline & $>2000$ & 70 & 60 & 1.00 & 1.00 \\
\hline \multirow{2}{*}{ Family knowledge } & Good & 299 & 340 & $0.40(0.15-1.08)$ & $0.37(0.12-1.10)$ \\
\hline & Poor & 13 & 6 & 1.00 & 1.00 \\
\hline \multirow{2}{*}{ Tooth cleaning } & Yes & 282 & 330 & $0.45(0.24-0.85)$ & $0.47(0.23-0.96)$ \\
\hline & No & 30 & 16 & 1.00 & 1.00 \\
\hline \multirow{2}{*}{ Sweet intake } & Yes & 268 & 273 & $1.83(1.95-2.81)$ & $1.94(1.22-3.09)$ \\
\hline & No & 38 & 71 & 1.00 & 1.00 \\
\hline \multirow{5}{*}{ Tea consumption } & Once a day & 221 & 256 & $1.01(0.59-1.71)$ & $0.92(0.51-1.63)$ \\
\hline & Twice a day & 54 & 40 & $1.58(0.83-3.00)$ & $1.47(0.73-2.97)$ \\
\hline & Three times a day & 4 & 9 & $0.52(0.14-1.87)$ & $0.38(0.97-1.52)$ \\
\hline & Once a week & 3 & 7 & $0.50(0.11-2.12)$ & $0.30(0.69-1.34)$ \\
\hline & Seldom & 29 & 34 & 1.00 & 1.00 \\
\hline \multirow{2}{*}{ Oral hygiene } & Poor & 104 & 157 & $1.65(1.20-2.26)$ & $1.59(1.12-2.26)$ \\
\hline & Good & 207 & 189 & 1.00 & 1.00 \\
\hline
\end{tabular}


Table 4. Factors associated with periodontal disease among young adolescents in Addis Ababa, December 2011.

\begin{tabular}{|c|c|c|c|c|c|}
\hline \multirow{2}{*}{\multicolumn{2}{|c|}{ Factor }} & \multicolumn{2}{|c|}{ Periodontal disease } & \multirow{2}{*}{ COR $(95 \%$ CI $)$} & \multirow{2}{*}{ AOR (95\% CI) } \\
\hline & & Yes & No & & \\
\hline \multirow{5}{*}{ Age } & 10 & 46 & 105 & $0.60(0.36-0.99)$ & $0.52(0.26-1.06)$ \\
\hline & 11 & 34 & 73 & $0.64(0.37-1.11)$ & $0.48(0.22-1.01)$ \\
\hline & 12 & 54 & 104 & $0.71(0.43-1.17)$ & $0.70(0.35-1.38)$ \\
\hline & 13 & 49 & 73 & $0.92(0.55-1.54)$ & $0.71(0.35-1.41)$ \\
\hline & 14 & 50 & 69 & 1.00 & 1.00 \\
\hline \multirow{3}{*}{ Type of school } & Government & 125 & 200 & 1.00 & 1.00 \\
\hline & Public & 38 & 47 & $1.29(0.79-2.09)$ & $1.87(0.97-3.62)$ \\
\hline & Private & 63 & 168 & $0.62(0.41-0.86)$ & $0.75(0.44-1.28)$ \\
\hline \multirow{4}{*}{ Mothers education } & Never & 74 & 105 & $3.05(1.39-6.68)$ & $3.17(1.14-8.81)$ \\
\hline & Grade 1 - 8 & 95 & 150 & $2.74(1.27-5.92)$ & $2.71(1.06-6.94)$ \\
\hline & Grade 9 - 12 & 51 & 115 & $1.92(0.86-4.26)$ & $1.89(0.73-4.87)$ \\
\hline & $>12$ & 9 & 39 & 1.00 & 1.00 \\
\hline \multirow{4}{*}{ Fathers education } & Never & 26 & 52 & $1.46(0.75-2.80)$ & $0.77(0.31-1.88)$ \\
\hline & Grade 1 - 8 & 63 & 96 & $1.91(1.10-3.33)$ & $1.21(0.58-2.55)$ \\
\hline & Grade 9 - 12 & 72 & 120 & $1.75(1.02-3.00)$ & $1.56(0.80-3.02)$ \\
\hline & $>12$ & 25 & 73 & 1.00 & 1.00 \\
\hline \multirow{3}{*}{$\begin{array}{l}\text { Number of family } \\
\text { living in the household }\end{array}$} & 2 to 4 & 64 & 136 & $0.74(0.49-1.12)$ & $0.64(0.36-1.14)$ \\
\hline & 4 to 6 & 88 & 160 & $0.87(0.59-1.28)$ & $0.89(0.53-1.50)$ \\
\hline & $>6$ & 81 & 129 & 1.00 & 1.00 \\
\hline \multirow{4}{*}{$\begin{array}{l}\text { Average monthly } \\
\text { expenditure }\end{array}$} & $<500$ & 34 & 59 & $1.39(0.79-2.45)$ & $1.12(0.47-2.64)$ \\
\hline & $500-1000$ & 67 & 113 & $1.43(0.88-2.32)$ & $1.05(0.52-2.10)$ \\
\hline & $1000-2000$ & 83 & 134 & $1.50(0.94-2.39)$ & $1.14(0.61-2.14)$ \\
\hline & $>2000$ & 38 & 92 & 1.00 & 1.00 \\
\hline \multirow{3}{*}{ Clean your teeth with } & Tooth brush & 72 & 149 & $0.56(0.28-1.15)$ & $0.55(0.18-1.66)$ \\
\hline & Mefakiya & 129 & 223 & $0.68(0.34-1.34)$ & $0.64(0.25-1.64)$ \\
\hline & Rinse with water & 17 & 20 & 1.00 & 1.00 \\
\hline \multirow{2}{*}{$\begin{array}{l}\text { Fluoride containing } \\
\text { tooth paste }\end{array}$} & Yes & 77 & 151 & $0.91(0.64-1.29)$ & $1.46(0.71-3.01)$ \\
\hline & No & 133 & 238 & 1.00 & 1.00 \\
\hline \multirow{2}{*}{ Oral hygiene } & Good & 49 & 212 & 1.00 & 1.00 \\
\hline & Poor & 183 & 213 & $3.7(2.57-5.37)$ & $3.13(1.98-4.93)$ \\
\hline
\end{tabular}

who clean their teeth 352 (57.7\%) uses a local twig/chewing stick which is commonly known as "Mefakiya". Studies have shown that traditional chewing stick is an effective way of maintaining good oral hygiene if the right type of shrub/twig and technique is used. The "Mefakiya" aids the mechanical removal of plaque, together with the antimicrobial effects [17] [18].

In this study, mother education was found to have an association with periodontal disease; this is in line with another research [2]. The prevalence of periodontal disease among those who have poor oral hygiene was also noted to be high. This confirms with the previously established association between poor oral hygiene and periodontal disease [2].

Some of the limitations of the study are: difficulties in using radiological examination at the field level might reduce the actual magnitude of dental caries, economic status is a very important factor; but it was difficult to measure households' income, mainly because people are not comfortable disclosing income. Hence, for this study average monthly expenditure was considered to assess economic status.

\section{Conclusions}

In conclusion, dental caries and periodontal diseases are highly prevalent oral health problems among young adolescents in Addis Ababa. To tackle the increasing prevalence of oral health problems it is important to stra- 
tegically introduce a community-based oral health education to inform the proper techniques and effective means of maintaining good oral hygiene.

Furthermore, health sector actors and policy makers ought to recognize the increasing trend of oral health problems, and should design and implement preventive activities including expansion and strengthening of oral health services.

\section{Competing Interests}

The authors declare that they have no competing interests.

\section{Author's Contributions}

Both authors HYB and AW participated in all steps of the study from its inception to the write up. Both authors have reviewed and approved the submission of the manuscript.

\section{Acknowledgements}

This study was financially supported by Addis continental Institute of Public Health (ACIPH), Ethiopia. The authors would like to gratefully thank the city administrative bodies for granting us permission to conduct the study. We sincerely thank all ACIPH staff, data collectors, and all study participants for their willingness to participate in the study.

\section{References}

[1] Petersen, P.E. (2003) The World Oral Health Report 2003-Continuouis Improvement of Oral Health in the 21st Century-The Approach of the WHO Global Oral Health Programme. Community Dentistry and Oral Epidemiology, 31, 3-24. http://dx.doi.org/10.1046/j..2003.com122.x

[2] Petersen, P.E. (2004) Improvement of Oral Health in Africa in the 21st Century-The Role of the WHO Global Oral Health Programme. African Journal of Oral Health, 1, 2-16. http://dx.doi.org/10.4314/ajoh.v1i1.31299

[3] Sheiham, A. (2005) Oral Health, General Health and Quality of Life. Bulletin of the World Health Organization, 83, 644.

[4] World Health Organization (1984) Prevention Methods and Programmes for Oral Diseases. Report of the WHO Expert Committee, World Health Organization Technical Report Series 713, WHO, Geneva.

[5] Batwala, V., Mulogo, E.M. and Arubaku, W. (2007) Oral Health Status of School Children in Mbarara, Uganda. African Health Sciences, 7, 233-238.

[6] Moynihan, P. and Petersen, P.E. (2004) Diet, Nutrition and the Prevention of Dental Diseases. Public Health Nutrition, 7, 201-226. http://dx.doi.org/10.1079/PHN2003589

[7] Knesevic, R., Skrobic, I., Celic, B., et al. (2009) Preventive Programme for Improving Oral Health in Primary School Children in Banjaluka. Serbian Dental Journal, 56, 123-126. http://dx.doi.org/10.2298/SGS0903123K

[8] Federal Democratic Republic of Ethiopia Population Census Commission (2008) Summary and Statistical Report of the 2007 Population and Housing Census, Population Size by Age and Sex. Addis Ababa.

[9] Al-Omiri, M.K., Al-Wahadni, A.M. and Saeed, K.N. (2006) Oral Health Attitudes, Knowledge and Behavior among School Children in North Jordan. Journal of Dental Education, 70, 179-187.

[10] Llodra, J.C., Christensen, L.B., Pitts, N.B., et al. (2008) Health Surveillance in Europe; Oral Health Interviews and Clinical Surveys: Guidelines. Lyon I University Press, Lyon.

[11] Lian, C.W., Phing, T.S., Chat, C.S., Shin, B.C., Baharuddin, L.H. and Che’Jalil, Z.B.J. (2010) Oral Health Attitudes, Knowledge, Attitude and Practice among Secondary School Students in Kuching, Sarawak. Archive of Orofacial Sciences, 5, 9-16.

[12] Simon, C., Tesfaye, F. and Berhane, Y. (2003) Assessment of Oral Health Status of School Children in Addis Ababa. Ethiopian Medical Journal, 41, 245-256.

[13] Petersen, P.E., Ahmed, N., Astrøm, A. and Skaug, N. (2007) Dental Caries Prevalence and Risk Factors among 12Year Old School Children from Baghdad, Iraq: A Post War Survey. International Dental Journal, 57, 36-44.

[14] Zhu, L., Petersen, P.E., Wang, H.Y., Bian, J.Y. and Zhang, B.X. (2003) Oral Health Knowledge, Attitudes and Behavior of Children and Adolescents in China. International Dental Journal, 53, 289-298. http://dx.doi.org/10.1111/j.1875-595X.2003.tb00762.x 
[15] Fantaye, W., Stretton-Downes, S., Tekle-Haimanot, R. and Melaku, Z. (2005) Dental Health. Epidemiology and Ecology of Health and Disease in Ethiopia, 767-779.

[16] Delgado-Angulo, E.K., Hobdell, M.H. and Bernabé, E. (2009) Poverty, Social Exclusion and Dental Caries of 12Year-Old Children: Across-Sectional Study in Lima, Peru. BMC Oral Health, 9, 1-6.

[17] Odongo, C.O., Musisi, N.L., Waako, P. and Obua, C. (2011) Chewing-Stick Practices Using Plants with Anti-Streptococcal Activity in a Ugandan Rural Community. Frontiers in Pharmacology, 2, 13.

[18] Seshathri, K. and Thiyagarajan, T. (2011) Antimicrobial Activity of Chewing Sticks of Jimma-Ethiopia against Streptococcus pyogens. Journal of Phytology, 3, 34-37. 
Scientific Research Publishing (SCIRP) is one of the largest Open Access journal publishers. It is currently publishing more than 200 open access, online, peer-reviewed journals covering a wide range of academic disciplines. SCIRP serves the worldwide academic communities and contributes to the progress and application of science with its publication.

Other selected journals from SCIRP are listed as below. Submit your manuscript to us via either submit@scirp.org or Online Submission Portal.
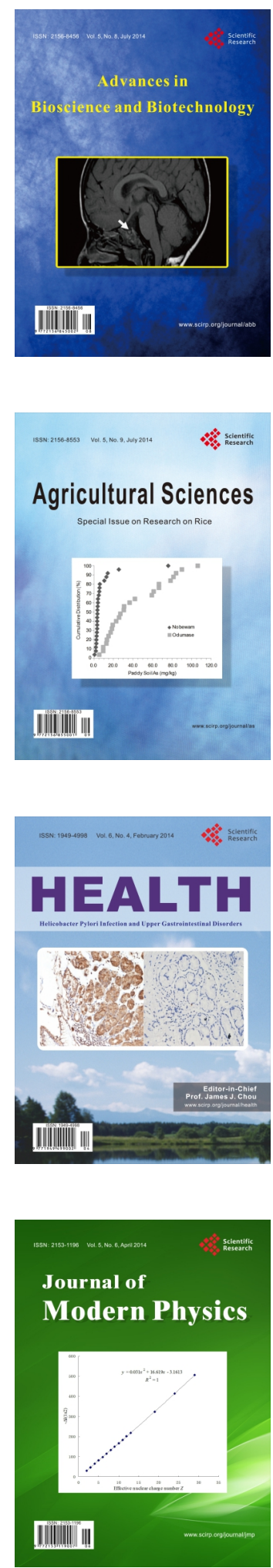
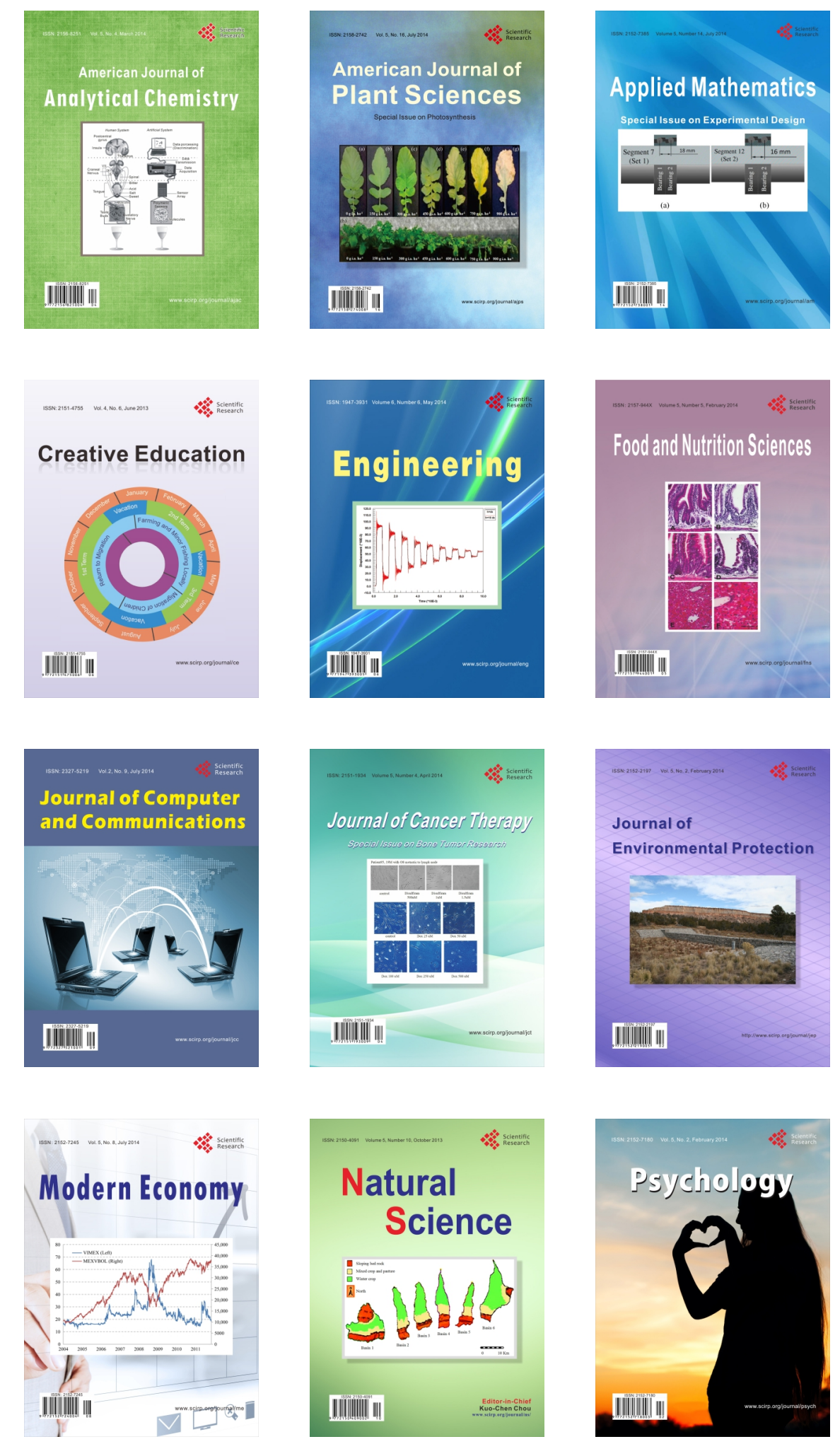